\title{
The spillway design for the dam's height over 300 meters
}

\author{
Weiwei Yao ${ }^{1, *}$, Yuansheng Chen ${ }^{1}$, Xiaoyi $\mathrm{Ma}^{2,3, *}$, and Xiaobin $\mathrm{Li}^{4}$ \\ ${ }^{1}$ Key Laboratory of Environmental Remediation, Institute of Geographic Sciences and Natural \\ Resources Research, China Academy of Sciences, Beijing, 100101, China. \\ ${ }^{2}$ Key Laboratory of Carrying Capacity Assessment for Resource and Environment, Ministry of Land \\ and Resources. \\ ${ }^{3}$ College of Water Resources and Architectural Engineering, Northwest A\&F University, Yangling, \\ Shaanxi 712100, P.R. China. \\ ${ }^{4}$ Powerchina Guiyang Engineering Corporation Limited, Guizhou, 550081, China.
}

\begin{abstract}
According the current hydropower development plan in China, numbers of hydraulic power plants with height over 300 meters will be built in the western region of China. These hydraulic power plants would be in crucial situation with the problems of high water head, huge discharge and narrow riverbed. Spillway is the most common structure in power plant which is used to drainage and flood release. According to the previous research, the velocity would be reaching to $55 \mathrm{~m} / \mathrm{s}$ and the discharge can reach to $300 \mathrm{~m}^{3} / \mathrm{s} . \mathrm{m}$ during spillway operation in the dam height over 300 $\mathrm{m}$. The high velocity and discharge in the spillway may have the problems such as atomization nearby, slides on the side slope and river bank, Vibration on the pier, hydraulic jump, cavitation and the negative pressure on the spill way surface. All these problems may cause great disasters for both project and society. This paper proposes a novel method for flood release on high water head spillway which is named Rumei hydropower spillway located in the western region of China. This paper has following components: Determining the type and the layout of the spillway through the perspectives of air entrainment, flow jet angle and water energy dissipation in flushing pond structure. The physical hydraulic model has been used to evaluate spillway design effects.
\end{abstract}

\section{Introduction}

In the last few decades, hydropower projects have developed rapidly in China. With the hydropower development booming in southwest regions of China, a number of hydropower projects will be built along the Lancang River, Jinsha River, Nu River and Brahmaputra. Spillway is the most important structure for releasing flooding and for energy dissipation [1, 2]. Spillway is also a main control factor to guarantee the hydropower plant operational safety. How to safely release huge flood discharge energy is always a problem and it's attracted researchers' attention to it. It is easy to cause disaster to the national economy due to improper spillway design. For example, the spillway in Sayan Shushenskaya hydropower

\footnotetext{
* Corresponding author (Xiaoyi Ma): science_research@126.com; weiweiyao@ignsrr.ac.cn
} 
station in Russia has destroyed due to the improper spillway design and operation. India Bukla Hydropower Station, the energy dissipation tank would destroyed when the flood discharge ponds have a lot of hydrodynamic pressure at the bottom of the water. In the United States, the Dvorshkon hydropower station also causes the structural destruction of the energy dissipation tank. In China, The Spillway on Yupang, Ertan, Liujiaxia and Longyangxia hydropower station also meet damaged due to cavitation and hydrodynamic pressure [3,4]. Therefore it is has significantly meaning to study hydraulic characteristic on spillway especially the hydropower projects with high water head and large discharge.

In the dam project, the spillway design must solve a series of hydraulics problems based on numerical and/or physical model. However, for the flow velocity which is higher than 25 $\mathrm{m} / \mathrm{s}$, there is no suitable software or numerical model which could well simulated. The maximum velocity in many spillways are high than $25 \mathrm{~m} / \mathrm{s}$. For example, the maximum velocity in Dongqin hydropower project is $37 \mathrm{~m} / \mathrm{s}$, the maximum velocity in Dongfeng hydropower project is $32 \mathrm{~m} / \mathrm{s}$, the maximum flow velocity of Hongjiadu Hydropower Station is $34 \mathrm{~m} / \mathrm{s}$, the maximum flow velocity of Nolek spillway is $59 \mathrm{~m} / \mathrm{s}$, and the maximum velocity in Glutinous Rolling spillway is $53 \mathrm{~m} / \mathrm{s}[5,6]$. So, the physical model is the suitable option for the spillway design. In order to decrease the damage of high-speed flow, increasing concrete strength, aeration devices, and energy dissipation options are very important components on spillway design.

The aim of this paper is to design the suitable spillway for Rumei hydropower project with the maximum discharge $13617 \mathrm{~m}^{3} / \mathrm{s}$, with the water head $272 \mathrm{~m}$, and with the dam height $315 \mathrm{~m}$. The spillway design is focus on three parts: aeration devices types; water tough design; and energy dissipation tank design.

\section{Material and method}

In order to fulfill the industrial energy requirement and to increase the share of renewable energy, China has proposed 13 hydropower construction bases from 1989 and expected to complete in 2050. The Rumei hydropower project is belonging to one of the hydropower construction base named Lanchang-Mekong River Base with $3.83 \times 10^{10} \mathrm{~m}^{3}$ on reservoir capacity and $315 \mathrm{~m}$ of the dam height. According the plan, the Rumei hydropower project is expected to start construction in 2025 and completed in 2040 [7]. The location, scheme of hydropower project layout, and the vertical section of spillway is shown in Figure 1.

In this study, a standard-shaped spillway with high water head has been proposed for Rumei hydropower projects. Several physical model were setup for the optimal spillway design. In this paper, we focus on how to reduce the subatmospheric crest pressure on spillway with a aeration devices. We also focus on the crest bridges design and energy dissipation with the physical model.

\section{Result and discussion}

\subsection{Aeration devices types}

The spillway surfaces with high speed flow may cause cavitation damage of spillway and the aeration devices tends to deflect the high velocity flow away from the spillway surface. The aeration device in the spillway of Rumei hydropower projects is show as Figure 2. It can be noticed that with the side and central vert tube, the air demand in the spillway are expected 
to fulfill. The ridge of the aeration device could guarantee the full integration of flow and air. This aeration device has been verified in Dongqing and Hongjiadu hydropower projects with good effects on spillway protection.

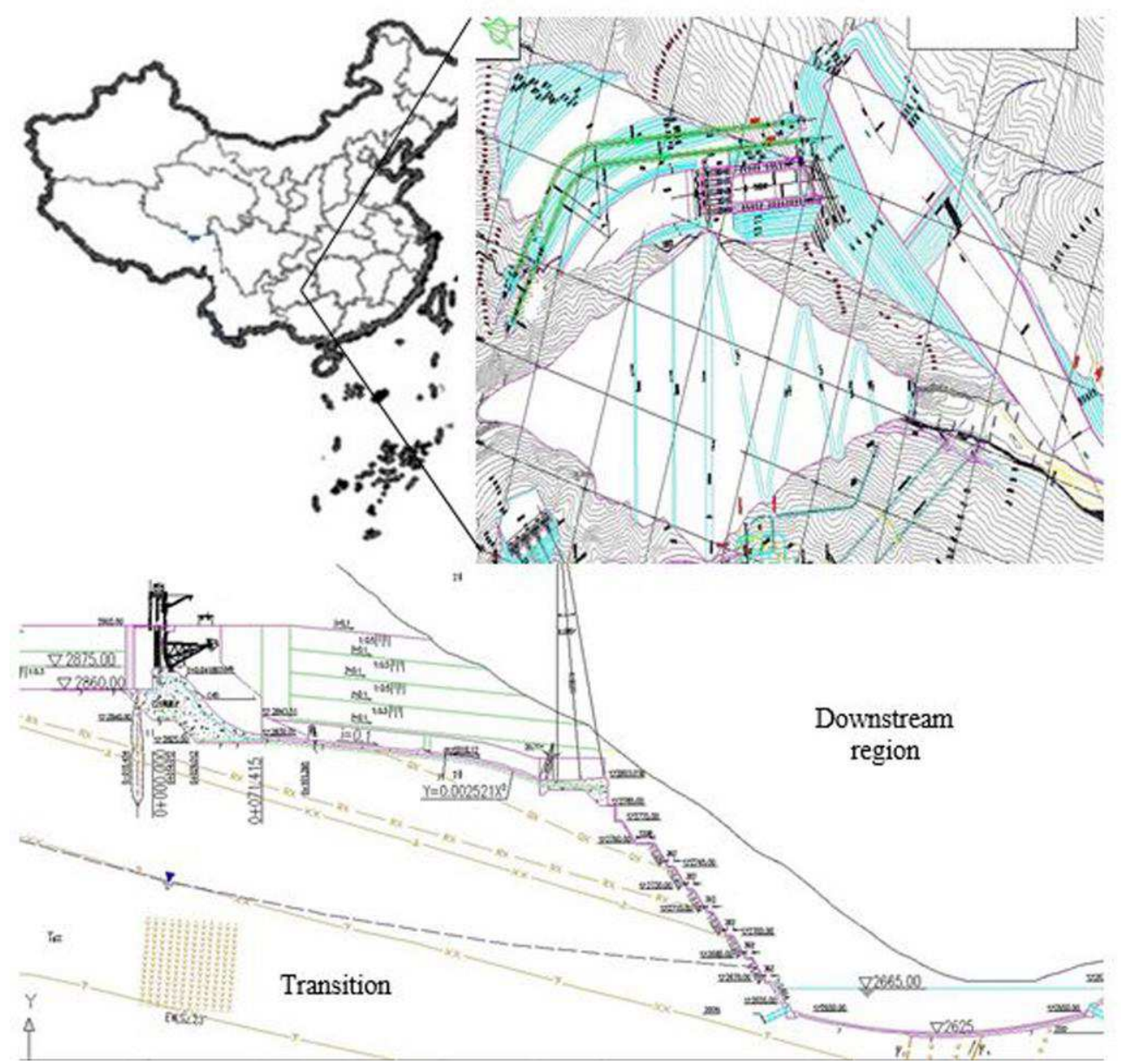

Fig. 1. Spillway layout and the vertical section of the spillway. 


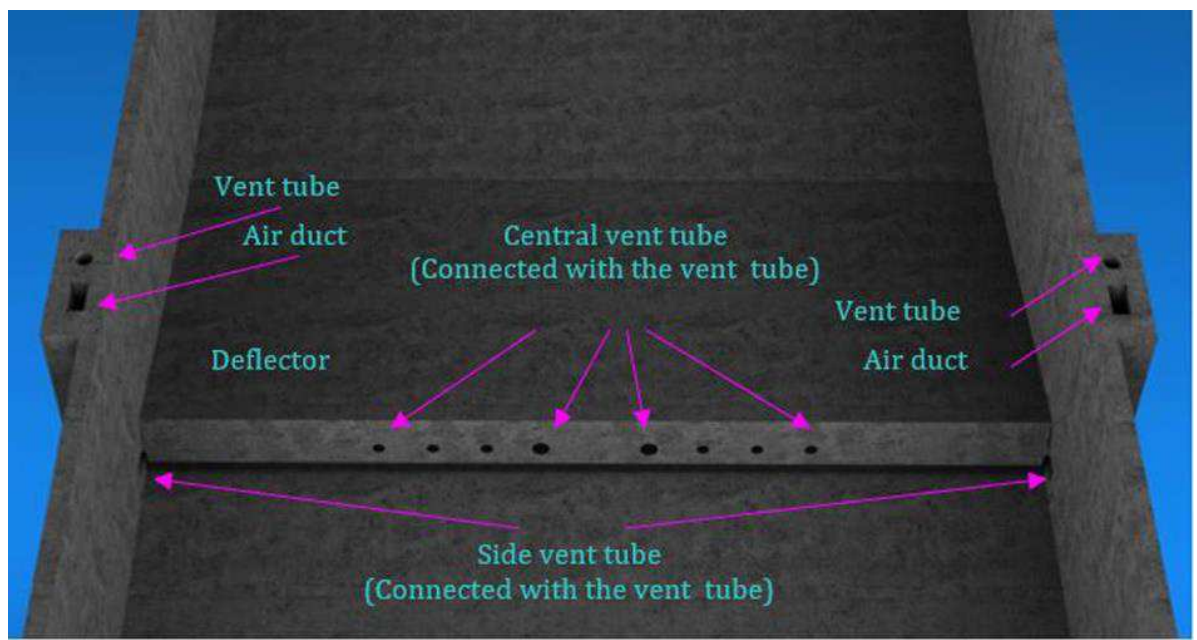

Fig. 2. The designing of aeration devices.

\subsection{Flow pattern over the spillway crest}

The flow pattern based on two types of spillway crest are shown in Figure 3. It can be noted that there are two lays of the water flow in Figure 3 (a). However, the design of this type of spillway crest easily to result in landslide and intensive atomization. Based on the design of Figure 3 (b), there flow concentration and atomization problems are still existing. It is also easily to increase the hydrodynamic load on the spillway bottom. Thus, this two types of spillway crest cannot fulfill the energy dissipation on Rumei hydropower project.

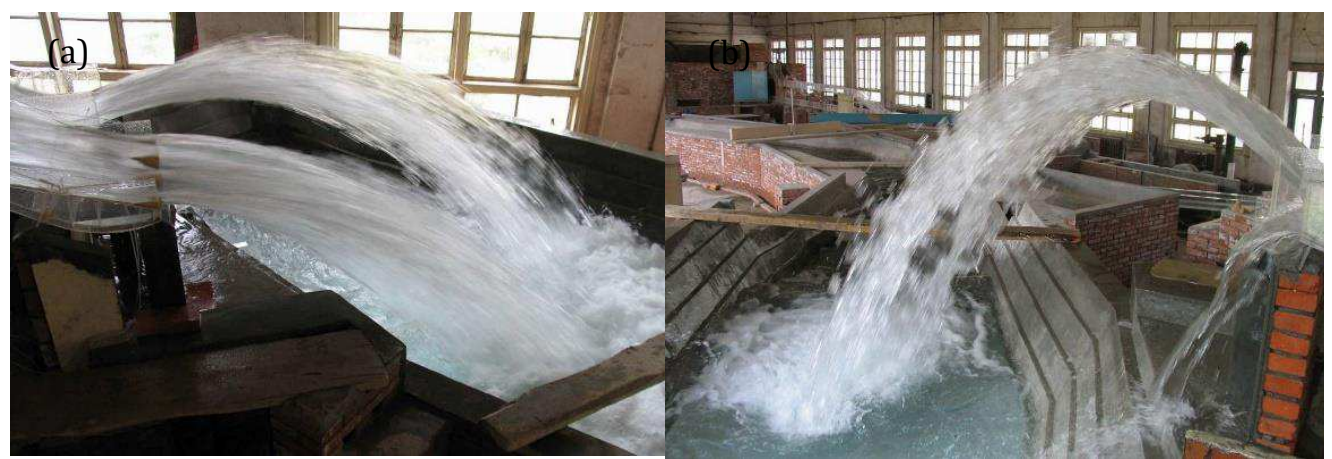

Fig. 3. The physical model of flow pattern over two types of spillway crest.

\subsection{Suitable energy dissipation based on optimal spillway design}

In order to achieve good energy dissipation effects, the spillway were divided into three separate drains and the detailed designed size as well as the physical model are shown in Figure 4. With this design, the energy dissipator is also divided into three independent energy dissipators. Eeah of them can be individually desined and could significantly increase the energy disspiation effects. 


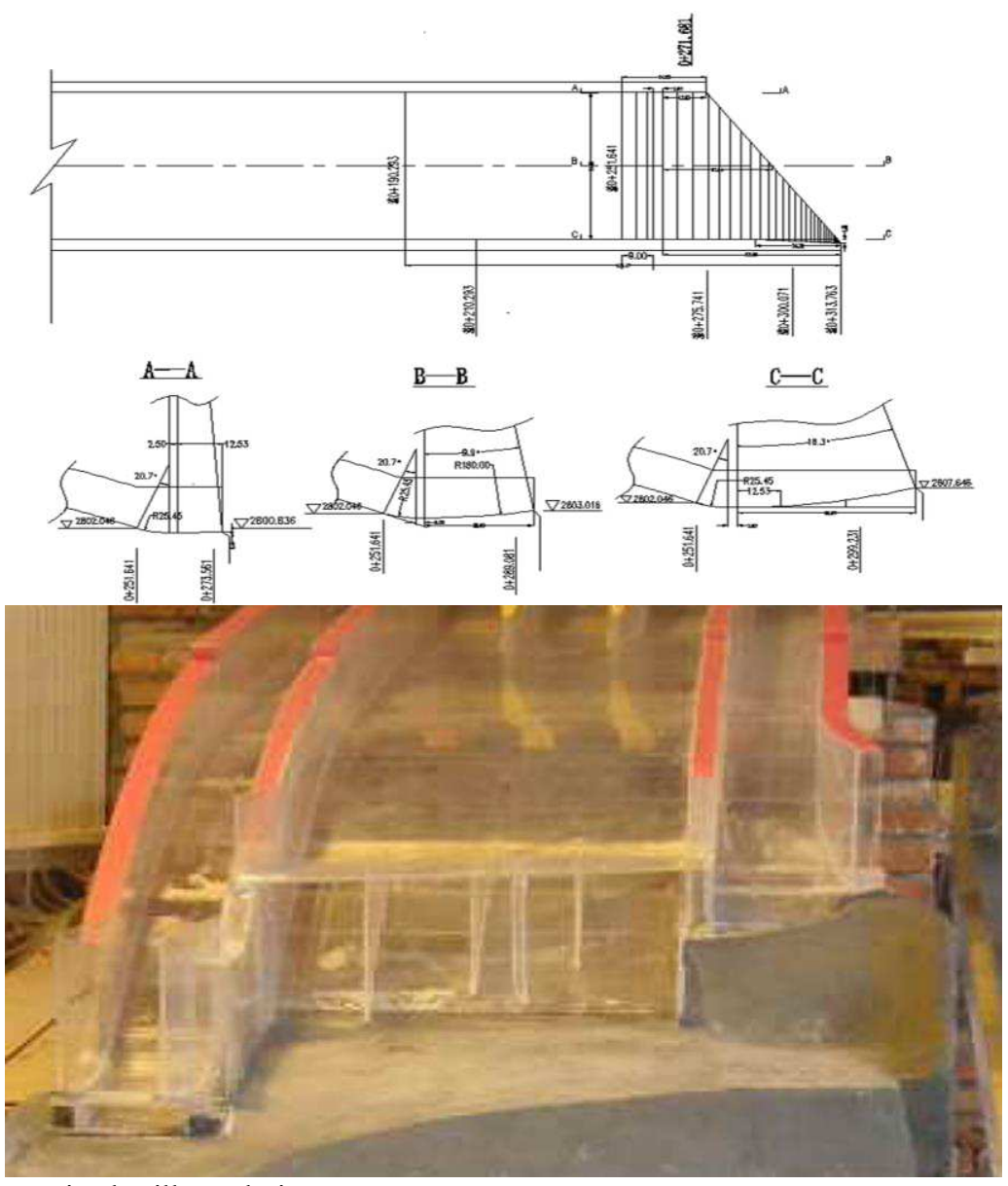

Fig. 4. The optimal spillway design.

The flow pattern of the physical model based on different discharge are shown in Figure 5. Based on the physical model experiments, it's can be easily noticed that the flow pattern on all shemes are fully developed and the enegy dissipation effects is very good. It is also indicated that the flow impact region are evenly distributed along the tank which means that the flow concentration and velocity concentration can be avoid.

In order to accurately and comprehensively analyze the high-flow impact pressure of on the bottom, pressure-measuring points are arranged in 17 rows and $5 \sim 7$ columns on the floor were set to measure the pressure. The bottom pressure sensor layout is shown in Figure 6 and the measurement value are shown in Table 1.

It can be noted from the Table 1 that the pressure values changes are very slightly and no significant pressure difference between adjacent measuring points. This suggested that there is no large hydrodynamic impact pressure existing on the optimal energy spillway design. It is also suggested that the optimal spillway design has good energy dissipation effects. 

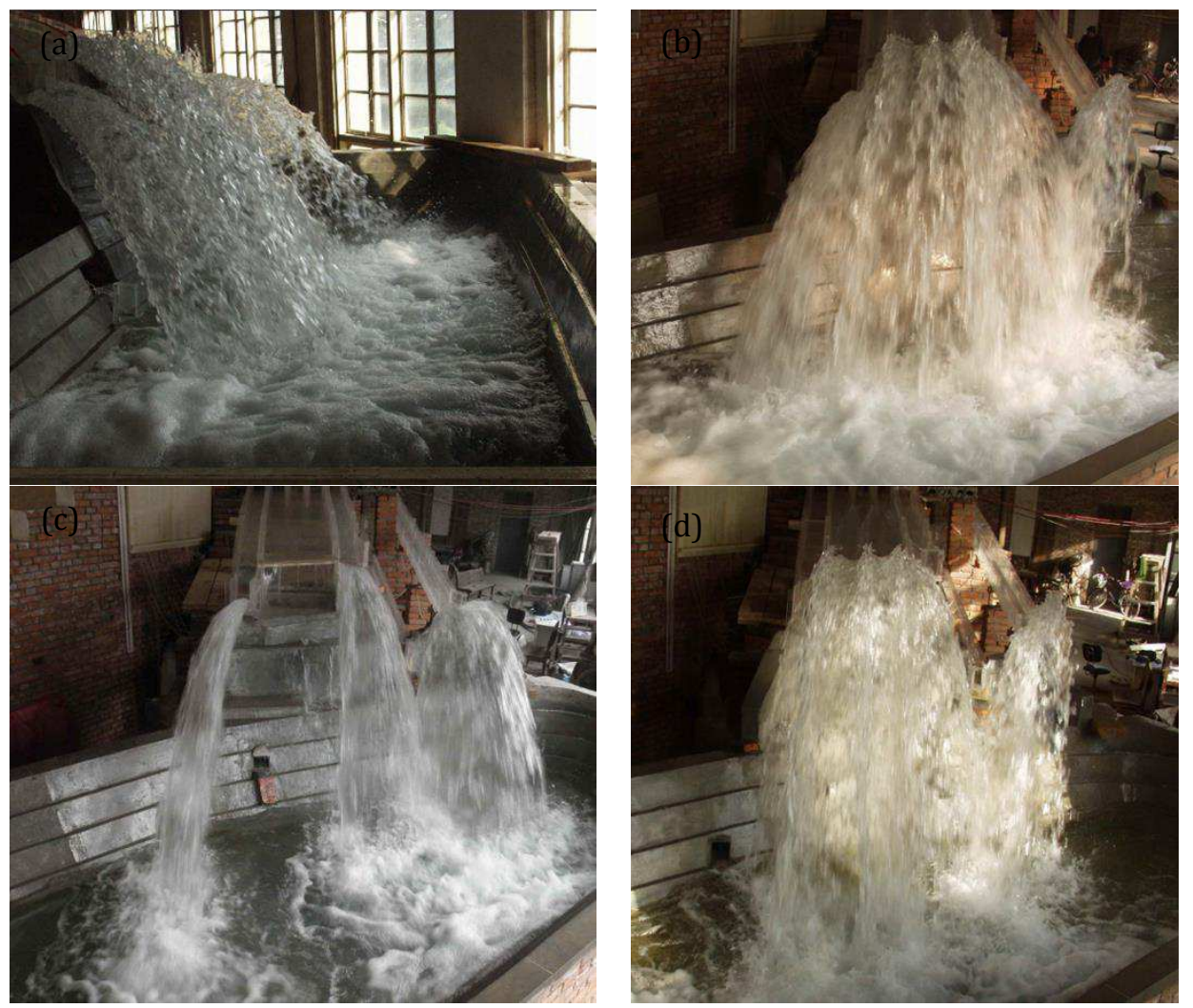

Fig. 5. The flow pattern based on optimal energy dissipation design.

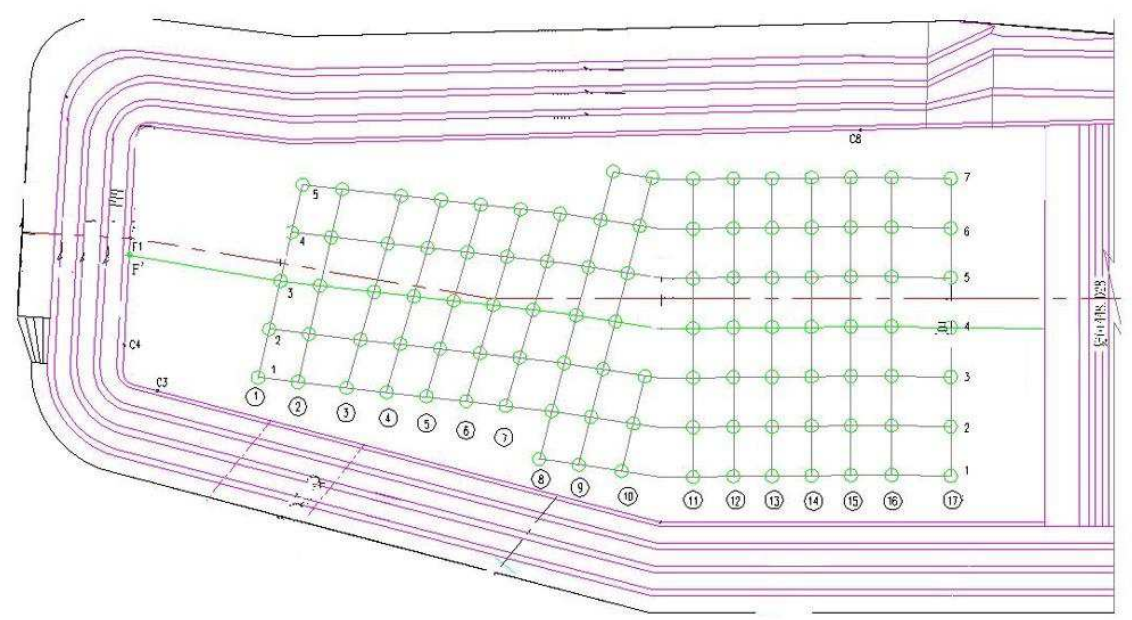

Fig. 6. The bottom pressure sensor layout map. 
Table 1. The measurement value of pressure on spillway bottom.

\begin{tabular}{|c|c|c|c|c|c|c|c|c|c|c|}
\hline & 1 & 2 & 3 & 4 & 5 & 6 & 7 & 8 & 9 & 10 \\
\hline 1 & 20.7 & 21.42 & 23.22 & 24.21 & 25.65 & 27 & 28.26 & 24.57 & 34.93 & 25.2 \\
\hline 2 & 22.77 & 23.49 & 25.02 & 26.28 & 27.9 & 29.88 & 31.05 & 30.15 & 29.7 & 30.06 \\
\hline 3 & 23.04 & 23.85 & 25.47 & 26.64 & 28.98 & 30.24 & 32.4 & 31.77 & 32.94 & 33.03 \\
\hline 4 & 22.14 & 22.95 & 24.84 & 25.92 & 28.53 & 28.35 & 31.23 & 33.12 & 34.29 & $/$ \\
\hline 5 & 20.88 & 20.88 & 22.68 & 24.75 & 25.29 & 25.02 & 28.44 & 33.66 & 34.56 & $/$ \\
\hline 6 & $/$ & $/$ & $/$ & $/$ & $/$ & $/$ & $/$ & 30.78 & 27.27 & $/$ \\
\hline 7 & $/$ & $/$ & $/$ & $/$ & $/$ & $/$ & $/$ & 27 & 27.27 & $/$ \\
\hline & 11 & 12 & 13 & 14 & 15 & 16 & 17 & & & \\
\hline 1 & 25.2 & 26.1 & 26.19 & 25.2 & 2640.5 & 26.37 & 28.53 & & & \\
\hline 2 & 30.15 & 30.87 & 31.05 & 29.97 & 29.7 & 31.59 & 34.92 & & & \\
\hline 3 & 32.76 & 32.85 & 33.21 & 32.85 & 32.13 & 33.48 & 37.35 & & & \\
\hline 4 & 34.56 & 33.93 & 35.55 & 32.94 & 32.4 & 34.74 & 37.8 & & & \\
\hline 5 & 34.83 & 37.8 & 35.19 & 34.56 & 30.87 & 34.56 & 37.35 & & & \\
\hline 6 & 32.76 & 33.3 & 33.03 & 32.67 & 31.95 & 32.85 & 36 & & & \\
\hline 7 & 27.9 & 28.35 & 28.26 & 27.99 & 27.9 & 27.99 & 29.88 & & & \\
\hline
\end{tabular}

* unite is kpa

\section{Conclusion}

In the hydropower project with high water head, the spillway energy dissipation and antiflood safety are paid much attention. It is very difficult to design a high-head flood discharge energy dissipation system for a dam with over $300 \mathrm{~m}$ height. In this study, we did some primary research on the spillway design based on physical model. The following research would focus on the numerical simulation and repeat the physical model. It is also necessary to grasp and follow a safe degree, maximum flow rate control, control of aeration and energy dissipation, control of atomization.

\section{References}

1. J. Lian, M. Yang., Beijing China Water Power Press. J. E 01 (2008)

2. S. Sun, Eur. Phys. J. of China Water resources and Hydropower Research, 7 (2) (2009)

3. H. Wang, G. Dai, Progress in Water Conservancy and Hydropower Engineering 4, (2004)

4. Q. Shi, S. Pan, Journal of Hydraulic Engineering, 3 (2013)

5. R. Xiao, Hydropoer station design, 4, (2008)

6. Q. Yang, Water power generation, (1995)

7. W. Yao, J. Total Research (2018). (to be published) 